\title{
PRODUCT DEVELOPMENT BY USING MODULAR DESIGN STRUCTURE MATRIX
}

\section{Puneet Saini \\ Department of Production Engineering \\ Birla Institute of Technology, Mesra,}

Ranchi, India

\author{
Ayush Dubey \\ Department of Production Engineering \\ Birla Institute of Technology, Mesra, \\ Ranchi, India
}

\author{
Vijay Pandey \\ Department of Production Engineering \\ Birla Institute of Technology, Mesra, \\ Ranchi, India
}

\begin{abstract}
Product development processes changes with the changing market trend. Green design and modular design both plays important role for the product development processes. In this research Design Structure Matrix (DSM) approach was used to group different modular parts together to obtain optimized module efficiency. Furthermore, this research proposed the use of DSM to find the result of coupled task. Component based DSM was used to describe the interaction between the parts. Loop analysis was utilized to decrease the number of module group and to find the most suitable group dividing approach. MatLab software was used to establish connections between all the individual components for Green DSM development.
\end{abstract}

Keywords- Modular design, Design Structure Matrix, Component based DSM, Loop analysis.

\section{INTRODUCTION}

Modular design is a strategic approach to product development, that is based on the decomposition of products into independent sub assemblies and components referred to as product modules.[1].To stay competitive companies have to introduce new products with the changing consumer requirement. This approach helps companies to introduce new product with updated capability into the market by modifying different modules from the existing design. For the positive development of a product, because of the lack of complete component information, it is necessary to build product system from customer needs analysis that embodies information sequence, iteration and feedback. The use of DSM can achieve such goal.

The Design Structure Matrix (DSM - also known as the dependency structure matrix, dependency source matrix, and dependency structure method) is a method for representing and analyzing system models in a variety of application areas. A DSM is a square matrix (i.e., it has an equal number of rows and columns) that shows relationships between elements in a system. Since the behavior and value of many systems is largely determined by interactions between its constituent elements, DSMs have become increasingly useful and important in recent years. Relative to other system modeling methods, a DSM has two main advantages:

- It provides a simple and concise way to represent a complex system.

- It is amenable to powerful analyses, such as clustering (to facilitate modularity) and sequencing (to minimize cost and schedule risk in processes).
There are three basic building blocks for describing the relationship among system elements: parallel (or concurrent, sequential (or dependent) and coupled (or interdependent) as shown in figure 1 :

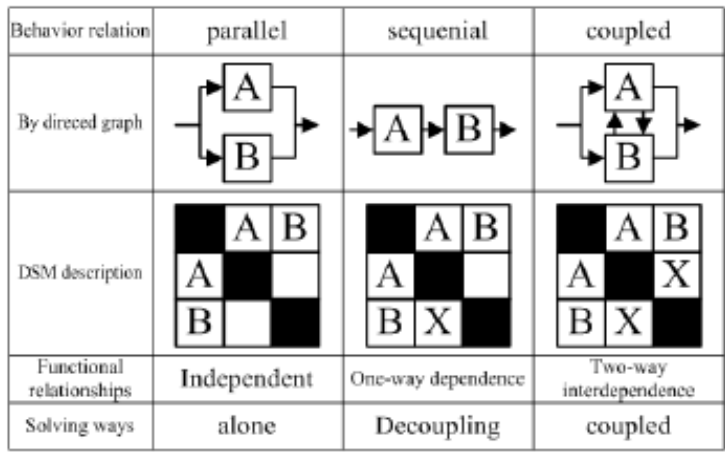

Figure 1: Relationship among system elements

The DSM is a popular representation and analysis tool for system modeling, especially for purposes of decomposition and integration. There are two types of DSMs: static and time-based. Static DSMs represent system elements existing simultaneously, such as components of product architecture or groups in an organization. Static DSMs are usually analyzed with clustering algorithms. In time-based DSMs, the ordering of the rows and columns indicates a flow through time and terms like "feed forward" and "feedback" become meaningful when referring to interfaces [2]. Time-based DSMs are typically analyzed using sequencing algorithms [3].

There are four types of DSMs: component based, teambased, activity-based and parameter-based and each of the four applications is applied to system decomposition and/or integration problem in the Table 1 .

Among the four types of DSMs, component-based DSM is used for modeling system architectures based on components and/or subsystems and their relationships. The component-based DSM represents the system in terms of the relationships between its constituent components and the represented system is decomposed into several sub-systems to define modules of the system. In general, modules can be defined by the following three steps [2]: 
ELK

Asia Pacific Journals

1) Decompose system into elements: Describe the product concept in terms of functional and/or physical elements which achieve the product's functions.

2) Document the interactions between elements: Identify the interactions which may occur between the functional and physical elements.

3) Cluster the elements into modules: Cluster the elements into chunks based on criteria set by the overall product design strategy of the team. These chunks then define the product architecture and system team structure.

Table 1: Types of DSM

\begin{tabular}{|c|c|c|c|}
\hline $\begin{array}{c}\text { Dsm } \\
\text { Data } \\
\text { types }\end{array}$ & Representation & Application & $\begin{array}{c}\text { Analysis } \\
\text { Method }\end{array}$ \\
\hline $\begin{array}{c}\text { Task- } \\
\text { based }\end{array}$ & $\begin{array}{c}\text { Task/Activity } \\
\text { input/output } \\
\text { relationships }\end{array}$ & $\begin{array}{c}\text { Project } \\
\text { scheduling, } \\
\text { activity } \\
\text { sequencing, } \\
\text { cycle time } \\
\text { reduction }\end{array}$ & $\begin{array}{c}\text { Partitioning, } \\
\text { Tearing, } \\
\text { Banding, } \\
\text { Simulation and } \\
\text { eigenvalue } \\
\text { analysis. }\end{array}$ \\
\hline $\begin{array}{c}\text { Paramet } \\
\text { er } \\
\text { based }\end{array}$ & $\begin{array}{c}\text { Parameter } \\
\text { decision points } \\
\text { and necessary } \\
\text { precedents }\end{array}$ & $\begin{array}{c}\text { Low level } \\
\text { activity } \\
\text { sequencing and } \\
\text { process } \\
\text { construction. }\end{array}$ & $\begin{array}{c}\text { Partitioning, } \\
\text { Tearing, } \\
\text { Banding, } \\
\text { Simulation and } \\
\text { Eigenvalue } \\
\text { analysis. }\end{array}$ \\
\hline $\begin{array}{c}\text { Team } \\
\text { based }\end{array}$ & $\begin{array}{c}\text { Multi-team } \\
\text { interface } \\
\text { characteristics }\end{array}$ & $\begin{array}{c}\text { Organizational } \\
\text { design, interface } \\
\text { management, } \\
\text { team integration }\end{array}$ & Clustering \\
\hline $\begin{array}{c}\text { Compo } \\
\text { nent } \\
\text { based }\end{array}$ & $\begin{array}{c}\text { Multi } \\
\text { component } \\
\text { relationships }\end{array}$ & $\begin{array}{c}\text { System } \\
\text { architecting, } \\
\text { engineering and } \\
\text { design }\end{array}$ & Clustering \\
\hline
\end{tabular}

A component-based DSM interacts among elements in system architecture. The number and definitions of the interaction types can be different by the given design problem. [2] suggested four types as follows:

Spatial: A spatial-type interaction identifies needs for adjacency or orientation between two elements.

Energy: An energy-type interaction identifies needs for energy transfer between two elements.

Information: An information-type interaction identifies needs for information or signal exchange between two elements.

Material: A material-type interaction identifies needs for materials exchange between two elements.

The interactions should describe the strengths of relationships between elements. [2] Suggested a fivepoint scale $(-2,-1,0,1,2)$ based on the relative need for each interaction type as shown in fig. 2. After the interactions have been quantified, the next step is to cluster the elements into modules.
ELK Asia Pacific Journals - Special Issue ISBN: 978-81-930411-4-7

\begin{tabular}{|c|c|c|c|}
\hline Elements: & \multicolumn{3}{|c|}{ Radiator and Engine Fan } \\
\hline $\begin{array}{l}\text { Function: } \\
\text { (Radiator) }\end{array}$ & \multicolumn{3}{|c|}{$\begin{array}{l}\text { The radiator dissipates excess engine heat, } \\
\text { via forced convection, to the outside } \\
\text { surroundings. }\end{array}$} \\
\hline $\begin{array}{l}\text { Function: } \\
\text { (Engine Fan) }\end{array}$ & \multicolumn{3}{|c|}{$\begin{array}{l}\text { The engine fan draws outside air into the } \\
\text { engine compartment. }\end{array}$} \\
\hline Relationship: & \multicolumn{3}{|c|}{$\begin{array}{l}\text { The engine fan provides airflow across the } \\
\text { radiator. They are located in close } \\
\text { proximity for design efficiency and due to } \\
\text { space management constraints. }\end{array}$} \\
\hline Score: & \begin{tabular}{r|} 
Spatial: +2 \\
Information: 0
\end{tabular} & $\begin{aligned} \text { Energy: } & 0 \\
\text { Materials: } & +2\end{aligned}$ & \\
\hline
\end{tabular}

Figure 2: Relationship table of climate control system of an auto mobile (Adopted from Pimmler and epinger 1994)

Figure 3 illustrates an example of the component-based DSM of a climate control system of an automobile system and figure 4 shows the clustered DSM.

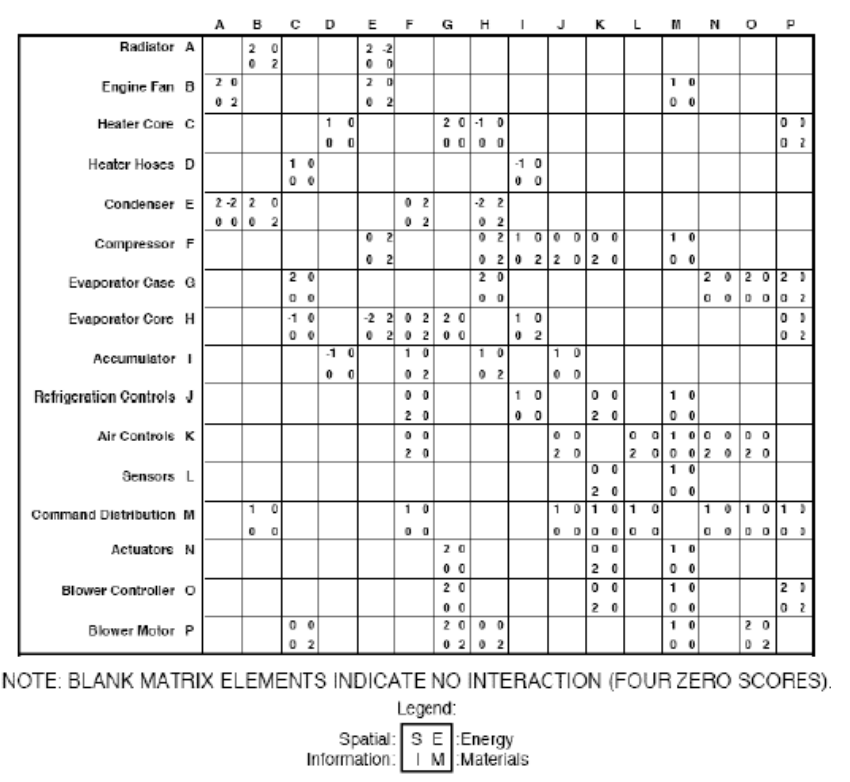

Figure 3 : DSM of the Climate control system example (Adopted from Pimmler and Epinger 1994) 
ELK

\section{Asia Pacific Journals}

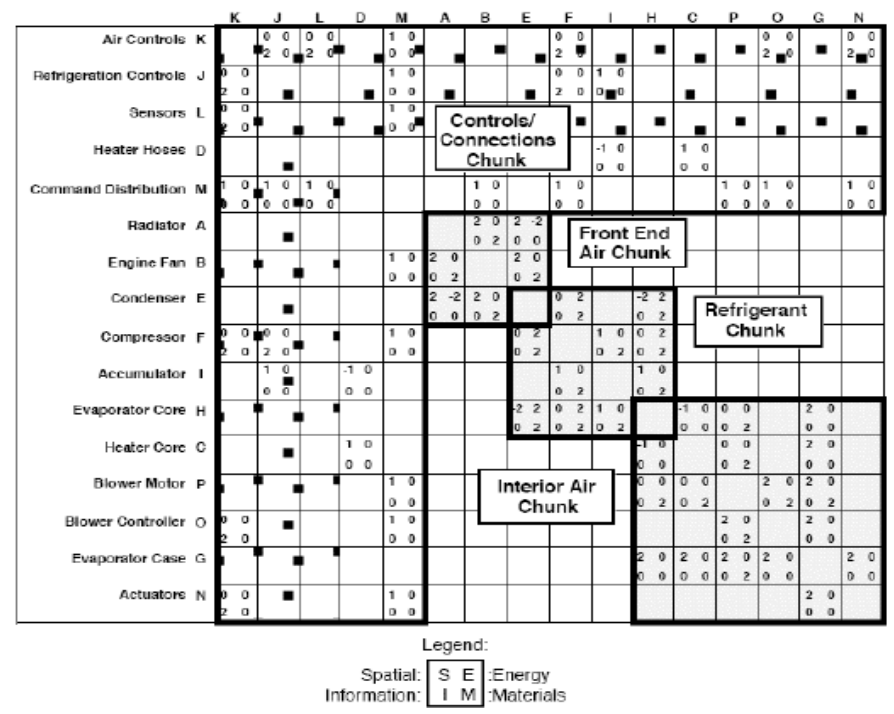

Figure 4: Clustered DSM of the climate control system example (Adopted from Pimmler and Eppinger 1994)

\section{PAPER SURVEYS}

Most of the research into the theory behind modularity originates from Suh's [4] independence axiom, which states that, "In good design the independence of functional requirements is maintained." Ulrich and tung [5] define modularity in terms of two characteristics of product design:1) Similarity between the physical and functional architecture of the design and 2) Minimization of incidental interaction between physical components of the products. The advantages and wide application of modular design make large number of researcher make researches on it. Current research mainly focuses on its technical difficulties such as modular planning, module clustering, module organization, module configuration, and module variation. Thomas gaertner et al[6] used DSM methodology that improved the planning of project time and required resources, capacities and ensures tighter synchronization between project teams. Hu Qiao et al [7] established an autopoietic modular design module that controls the modular design process through the system level by analyzing the deficiencies of modular design process. Mengqui Li et al [8] defined a method based on sorting calculating and clustering analysis of DSM, according to the rules of rows exchange with same serial number. Although, DSM can define the modules from a viewpoint of relationships between components; the DSM cannot consider the relationships between functions and the components of the systems. To overcome these difficulties, a new decomposition method was introduced by Qiang Cheng et al [9] by giving an axiomatic design which was used to design the system and modules. Eul pyo hong et al [10] claims to represent a rational method to define modules considering relationships between
ELK Asia Pacific Journals - Special Issue ISBN: 978-81-930411-4-7

functional requirements and design parameters and interactions of design parameters within.

\section{Implementation}

This research used electric coffee maker as an example for green design. The body of the coffee maker is a very good example of a production module. A production module is one in which components have been grouped primarily because of similarity and dependence in their manufacturing and assembly processes. Production modules are designed independently of their function, but in the case of this coffee maker, the design incorporates both production and functional characteristics of modularity. The coffee maker's components are shown in figure 6 and an assembly diagram for the electric coffee maker is shown in figure 5 .

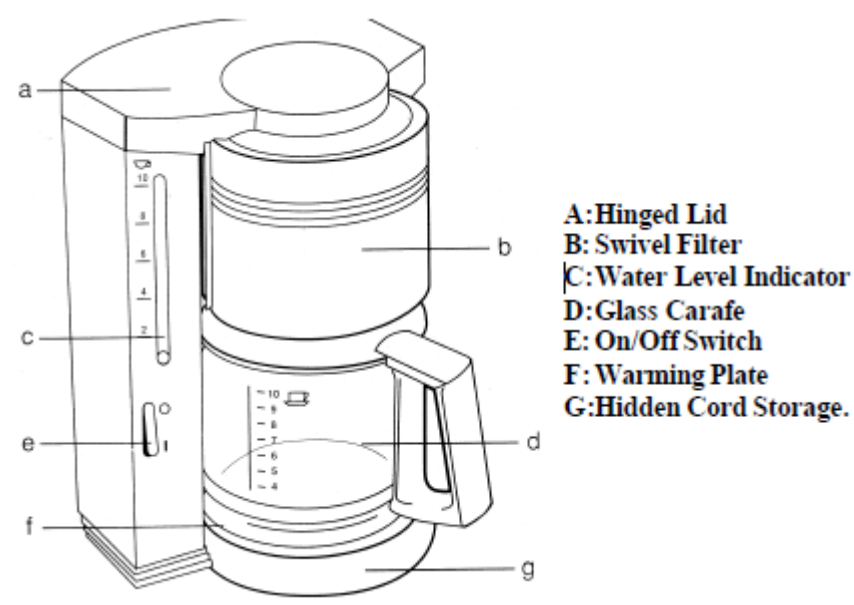

Figure 5: An assembly diagram for the electric coffee maker

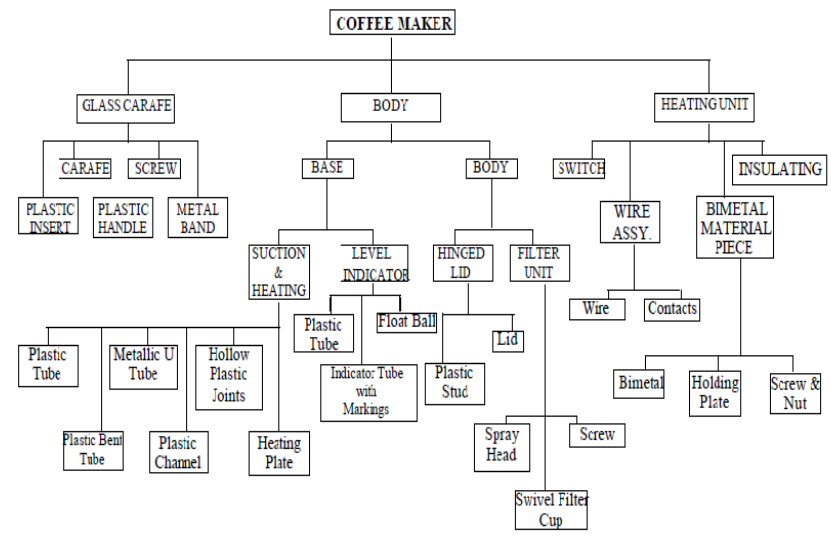

Figure 6: A component tree diagram for an electric coffee maker 


\section{- \\ ELK \\ Asia Pacific Journals}

Relationship between components was established. After cross-referencing with the component chart, "1" was placed in the matrix denoting the relationship between two components. For example " 1 " was placed in the matrix to denote the relationship between Heating plate and carafe.

The final completed groups within the DSM were described below.

1) Individual Task setup:

Columns separated and moved to the bottom right hand side of the matrix (X10, X9).

\section{2) Coupled Tasks Setup}

There were total of 9 groups: Individual Loop (X24, X16, $\mathrm{X} 14, \mathrm{X} 10)$ other loops (X11, X21, X25, X26) (X2, X3, $\mathrm{X} 5, \mathrm{X} 17)(\mathrm{X} 6, \mathrm{X} 7, \mathrm{X} 8)(\mathrm{X} 22, \mathrm{X} 23)(\mathrm{X} 19, \mathrm{X} 20)(\mathrm{X} 15$, $\mathrm{X} 18)(\mathrm{X} 12, \mathrm{X} 13)(\mathrm{X} 1, \mathrm{X} 4)$.

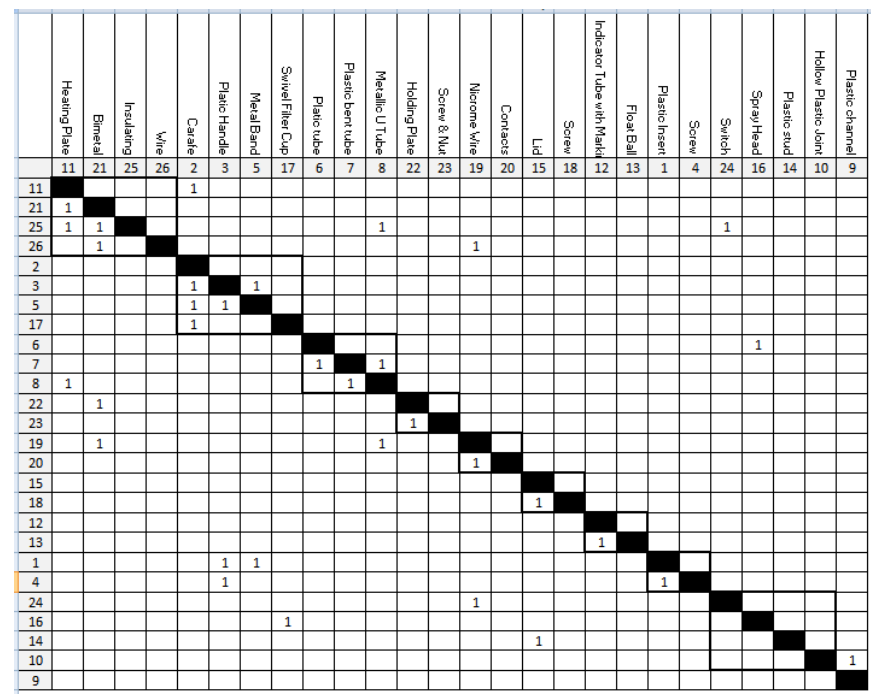

Figure 7: Coupling tasks with loops in electric coffee maker

As we can see from this research, loop analysis can easily separate the individual groups from the example electric coffee maker. A total of 9 groups were obtained from loop analysis. They were mentioned as follows.

1. First group contains coupled components. It consisted of component 11 - heating plate, 21 - bimetal, 25 insulating, 26 - wire. Bimetal was attached to the heating plate. The whole wiring should be insulated so the there should be no heat loss to the surrounding.

2. The second group also contained coupled components: 2 - carafe, 3 - plastic handle, 5 - metal band, 17 - swivel filter cup. Glass carafe can be made more modular by eliminating metal band and screw by providing a hook so that it can easily fix on to the groove on the carafe and it
ELK Asia Pacific Journals - Special Issue ISBN: 978-81-930411-4-7

can be assembled to the carafe with a strong bonding agent.

3. The third group contained coupled components: $6-$ plastic tube, 7 - plastic bent tube, 8 - metallic $U$ tube. Plastic tube was joined with swivel filter cup. Plastic bent tube was joined with metallic $U$ tube which was connected to the heating plate.

4. The fourth group contained coupled component: 22 holding plate, 23 - screw and nut. Holding plate was used to hold Bimetal and was hooked with screw and nut.

5. The fifth group contained coupled components: 19 nichrome wire, 20 - contacts. Nichrome wire was connected with Metallic $U$ tube which was used to transmit heat.

6. The sixth group contained coupled components: 15 lid, 18 - screw. Lid was placed on the top of the Swivel filter cup with the help of screw.

7. The seventh group contained coupled components: $12-$ indicator tube with marking, 13 - float ball. Indicator tube with marking was used to check the water level with float ball technique.

8. The eighth group contained coupled components: $1-$ plastic insert, 4 - screw. Plastic insert and screw were used to tighten carafe.

9. The ninth group contained individual components: $24-$ switch, 16 - spray head, 14 - plastic stud, 10 - hollow plastic joint. They exist individually of one another.

MATLAB as software is used to establish connections between all the individual components of green DSM development. The result allowed comparison and analysis of the various components in order to simplify the assembly process and complete modular design of the product.

\section{CONCLUSION}

In this paper the DSM is successfully applied to the electric coffee machine and a new design and assembly process is proposed. From the analysis of DSM results, it can be seen that the grouping methods will have a significant effect on later assembly steps. In order to obtain best solution, grouping methods can be applied to the actual product development processes. Loop analysis created 8 coupled component groups in addition to the group with individual components. These grouping allowed increased compatibility which in turn enabled faster assembly speed. Loop analysis can also achieve a 


\section{ELK}

\section{Asia Pacific Journals}

speedy disassembly of the product for a fast exchange of components without having to modify other groups. To make the design more greener Quality Function Deployment (QFD) can also be applied at the product development stage by considering the demands of the customers and finding out the materials which have an impact on environment.

\section{REFERENCES}

[1] K. Ulrich, and S. D. Eppinger, "Product design and Development". New York: McGraw-Hill, 1995.

[2] Pimmler, T.U., Eppinger, S.D., "Integration Analysis of Product

Decompositions," in Proceedings ASME $6^{\text {th }}$ International Conference on

Design Theory and methodology Minneapolis, MN, 1994.

[3] Browning, T. “Applying the Design Structure Matrix to System

Decomposition and Integration Problems: A Review and New Directions,"

IEEE Transactions on Engineering Management.

[4] Suh, "The principles of design" Oxford University Press. (1990).

[5] Ulrich k, Tung $\mathrm{K}$ Fundamentals of product modularity. In: A, editor issues

in Design/Manufacturing Integration, Proceedings ASME Winter Annual

Meeting Conference Atlanta, New York 1991.
ELK Asia Pacific Journals - Special Issue

ISBN: 978-81-930411-4-7

[6] Thomas Gaertner, Sebastian Sch Christomer M. Schlick, Carsten Zibull, “

Applying DSM methodology to improve the scheduling of functional

Integration of the automotive iindustry" $16^{\text {th }}$ international dependencies

and structural modeling conference, Paris, France (2014).

[7] Hu Qiao, Rong Mo, Ying Xiang Marco Franke, Karl A Hribernik, Klaus,

dieter Thoban, "An autopoietic approach for building modular design system"

[8] Mengqui Li, Dongying Li, "Modular decomposition method based on

Design structure Matrix and application"

Telekomnika, vol 10, No. 8 ,

December 2012.

[9] Qiang Cheng, Chuanming Xiao, Ligang Cai Guojun Zhang, "A product

Modular design method based on axiomatic design" . Proceedings of the

2012 IEEE $16^{\text {th }}$ International Conference on Computer Supported

Cooperative Work in Design.

[10] Eul- Pyo Hong, Gyung- Jin Park, "Modular design method using the independentt axiom and design structure matrix in the conceptual and detailed stage", $6^{\text {th }}$ International Conference on Axiomatic Design Deajeon, March 30-31, ICAD (2011). 